\title{
The Strategic Choice of Hangzhou to Cultivate the World Advanced Manufacture Industry Cluster
}

\author{
Haiyan $\mathrm{ZHOU}^{1,2^{*}}$ \\ ${ }^{1}$ China Center for Economic Research, East China Normal University, Shanghai 200062, China \\ ${ }^{2}$ General Manager Office, Zhejiang Huaxing Feather Manufacture Co., Ltd., Hangzhou 311305, China \\ *Corresponding author.Email:yanjiulilun8@126.com; zhouhaiyansh@hotmail.com
}

\begin{abstract}
The world advanced manufacture industry cluster is the advanced manufacture network with the same target and mutual benefit, integration and connection, which is established on basis of the professional work division requirement, and could occupy the industry highlands worldwide. The cultivation of the world advanced manufacture industry cluster is the process in which the Chinese industry moves towards the middle-to-high end of the global value chain. Only when China has a group of enterprises occupying the middle-to-high end of the global value chain, can the world advanced manufacture industry cluster form in the real sense. With the greater scale of our manufacture, many manufacture clusters have been formed in Hangzhou. However, the scale of the manufacture clusters in Hangzhou is not large, the industry level is not high, and the internal structure is not in good order. In a word, there are many unavoidable challenges for Hangzhou to cultivate the world advanced manufacture industry cluster, and they have to adopt effect solutions.
\end{abstract}

Keywords: advanced manufacture, cluster, Hangzhou, public policy, competitiveness, global value chain

\section{INTRODUCTION}

COVID-19, which has spread rapidly and enveloped most of the world, is a global public health crisis the likes of which we have not seen in a century. Is it easy to find work in China following the crisis? The cultivation of the world advanced manufacture industry cluster is necessary for Chinese industry to develop the middle-tohigh end of the global value chain in respect of the space structure and geographic layout. As one of the cities with the most economic future in China, Hangzhou locates in the manufacture golden belt of Zhejiang. In the recent ten years, with the superior geography advantage and the high end talents, the advanced manufacture has been the feature of Hangzhou, and thus Hangzhou has become the "brain" of Zhejiang intellectual made. As the pioneer and typical area of Chinese manufacture, Hangzhou should be the "Hangzhou height" and "Hangzhou model" in building the world advanced manufacture industry cluster. Under the background of new era and new strategy, only by focusing on the international competition and improving the international competitiveness, can Hangzhou forge a group of strong and powerful world advanced manufacture industry clusters.

\section{THE STRATEGIC MEANING TO CULTIVATE THE WORLD ADVANCED MANUFACTURE INDUSTRY CLUSTER IN THE DE-GLOBALIZATION BACKGROUND}

In recent years, with the effect of the European and American political and economic situation, the deglobalization has emerged ${ }^{[1]}$. During the recent decades, by releasing the market power, the economic globalization has promoted the rise the global manufacture system and the booming development of the global trade and production. While creating the prosperity and development, the economic globalization also brings the problems such as the poverty, conflict, unfair distribution, environment pollution, etc. Especially, with the break out of the global financial crises in 2008, the global economy did not see the satisfactory recovery in 2021 after 13 years' adjustment. In contrary, it is been trapped into continuous structural depression with the greater trade protectionism. The global multilateral mechanism is in low spirits; the various regional trade investment agreements are in debris; and the American and European immigration policy, investment policy and the supervision policy develop to the direction of de- 
globalization $^{[2]}$. The populism prevailing in the Europe and America considers that it is necessary to block the territory, emphasize the nationalism, home country first and regulate ourselves. This is actually the deglobalization. In the background of de-globalization, the worldwide new scientific-technological revolution and the industrial revolution are ready; the global economy and trade rules are being adjusted continuously; and the global manufacture has been in the full round competition period with more dimension, deeper and higher level.

Many strong industry countries are supported by the strong industry cluster, such as the US automobile industry cluster in the five-lake area, the aviation industry cluster in Seattle, the IT industry cluster in Silicon Valley. These clusters accumulates many excellent enterprises in the whole industry chain with strong industry impact and driving force, which establish the global hegemon position of the US in such industries ${ }^{[3]}$. Besides, the Japanese semiconductor cluster in Kyushu, Ksukuba science town, German Frankfurt chemistry industry cluster, the tool manufacture cluster in the Lemushite area and etc. are all famous industry clusters. Some new industrialized countries also put the building of the world first class industry cluster as the strategic emphasis to accelerate the industry development, such as the Jurong industry area and the national high technology industry area in Singapore, the Bangalore software outsourcing industry cluster in India, etc. These industry clusters are not only the important base of the national significant industry layout, but also the important representation of the national competitiveness ${ }^{[4]}$.

The Nineteenth Conference Report of CPC establishes that promoting our industry toward the middle-to-high end of the global value chain, and cultivating many world advanced manufacture industry clusters should be the new development notion and one of the important targets and tasks in constructing the modern economic system. This brand new strategic deployment is the significant decision made by the central party on basis of the present situation and main practice of the industry development, and the core connotation as well as the strategic direction of the modern economic system construction in the new era of the socialism with Chinese characteristics. From the perspective of the common rules for system change and the basic practice of the industry development, moving toward to the middle-to-high end of the global value chain is the urgent request for our industry to get rid of the difficult situation of low value chain end and value distribution; while the world advanced manufacture industry cluster is the necessary choice to move toward the middle-to-high end of the global value chain, the two of which are consistent internally. The world advanced manufacture industry cluster is to build the advanced manufacture network with the same target and mutual benefit, integration and connection and occupy the industry highlands worldwide, according to the professional work division requirement. Since the new century, China, especially the eastern coastal areas, grasp the WTO strategic opportunity and actively integrate into the global value chain and the global production network with the low element cost and the flexible mechanism. During such course, the manufacture industry grew larger and larger, and the manufacture industry cluster with obvious advantages and prominent technological capacity also developed rapidly. However, in recent years, with the rapid change and deep adjustment of the economic situation at home and abroad, relevant industries have encountered some problems, such as the short of resources, rise of cost and environment pollution ("troubles during the growing"), as well as the low end, peer competition, etc. Moreover, when moving toward the middle-to-high end of the global value chain, there are many serious challenges of "two ends out" and "two sides pressing", and the upgrade pressure of many manufacture industry clusters becomes larger and larger.

As the source of the recent national industry, Hangzhou is good at the entity economy. From the perspective of the quantity, form and the structure, the development of the manufacture industry in Hangzhou has shown the prosperity and the great power. As the tenth city with the GDP in the sum of millions of billions in the world, the new information technology develops vigorously; the industrial structure upgrades continuously; there are break outs for the new economy and finance practice; and there are continuous achievements for the new product integration. However, the problems such as the low product added value and brand impact, the weak core competitiveness and independent innovation ability; the middle level of the high end element accumulation and radiation capacity; the insufficient global value chain shaping and functional leaping ability are always unavoidable, and Hangzhou manufacture industry has been in the critical point of "overcoming difficulties". In the long run, the market competition in front of Hangzhou manufacture industry is international. The one who does not occupy the highlands of the international manufacture industry, could neither win the active position in future competition nor grasp the opportunity of the industry revolution to achieve the catch-up. Zhejiang has built the complete industry bases, with the complete chain and balanced layout. There is solid foundation to establish the world advanced manufacture industry clusters. As the capital of Zhejiang province, Hangzhou is able and also obliged to achieve the break out in upgrading the international competitiveness of the manufacture industry, and in turn obtain the initiative position in cultivating the world advanced manufacture industry cluster, and try to establish the "Hangzhou model" and "Hangzhou height". 


\section{THE INSUFFICIENCIES OF HANGZHOU IN CULTIVATING THE WORLD ADVANCED MANUFACTURE INDUSTRY CLUSTERS}

After many years' development, the industry clusters in Hangzhou have developed to certain scale with regional characteristics. There are groups of enterprises with strong economic and technological ability in the industries of electric information, information software, high end equipment manufacture, material internet, biology medicine, cloud computation, big data, etc. They develop well. The industry clusters such as the great east river, western city science and innovation are from a good starting point. They construct rapidly and show obvious accumulation effect, which brings strong potential for Hangzhou development. Take the automobile industry cluster in the great east river as an example. There are many automobile manufacture (the whole vehicle) enterprises in the great east river besides Chang'an Ford, Oriental Yulon, Guangzhou Gio, such as the global research head office of Geely. There are also some famous vehicle-parts manufacture enterprises, such as the US Jiangshen, the Canadian Magna, the Japanese Virginia, etc., as well as the vehicle electric chips research and development enterprises led by Zhongke Pilot, which has formed the relative complete automobile industry chain with the co-development of the whole vehicle production, vehicle research and development as well as the parts of the vehicle. However, there are still problems in the development of Hangzhou high end manufacture clusters.

For most of the traditional industries in Hangzhou, they do not form the complete industry chain; and do not have obvious economic and environment effect and international competitiveness. It is difficult for them to achieve the upgrade to "the high end of the manufacture industry". For example, although Xiaoshan textile industry has the full industry clusters from the chemical fiber production to the garment processing, the portion of the chemical fiber production in the structure is relatively large, forming the single structure based on the chemical fiber. There is no great relevance among relevant industries within the cluster, which still belongs to the "low end manufacture". In contrast, the Italian textile industry cluster covers the end products (such as the clothing), components (such as the synthetic fiber), relevant equipment (such as the textile machine) and the support service (such as the famous garment design), all of which are in the leading position in the global export with strong international competitiveness, which belongs to the real "high end manufacture".

At present, Hangzhou has four national development zones and six provincial development zones. Each county and city has their own industrial park, which establish good platform for the development of the high end manufacture industry clusters in Hangzhou. However, the problems such as the repeated construction and disorderly competition affect the scale and the specialization of the industry clusters. For example, compared to its neighbor Yu Hang economic technology development zone, Qian River economic technology development zone does not its own industry characteristic, and competes with Yu Hang economic technology development zone in the same nature. In the meantime, the enterprises in Qian River economic technology development zone have little relevance in the industry chain, and the park has difficulty in development, which affect the function of the industry platform.

Hangzhou industry chain does not have many links with international competitiveness. Especially that the key parts, the components and the technology still highly depend on the export. They do not occupy the "highlands of the manufacture industry". For example, the key parts and technology such as the servo system, the intellectual sensor, the instrument and the embedded industry control chips in the high end equipment manufacture mainly depend on the export. Many enterprises exist in the "processing" model. There are less invention patents with independent innovation and original innovation ability.

\section{THE STRATEGIC CHOICE OF HANGZHOU TO CULTIVATE THE WORLD ADVANCED MANUFACTURE INDUSTRY CLUSTERS}

The accurate grasp of the meaning and target of the world advanced manufacture industry cluster and cultivation of the world first class leading enterprises; the innovation, intellectual made and the product quality catching up with the international level are the goal of the world advanced manufacture industry cluster. Firstly, we should base on the China Made 2025 Hangzhou Action Outline and aim at the intellectual made and the core technology. From the horizontal level, we should accelerate the integration with the world advanced manufacture system; from the vertical level, we should activate the intellectual front end and terminal and thus develop to the high end. Secondly, it is necessary to emphasize the enterprise alliance, and strengthen the leading role of the backbone enterprises. By selecting the industry link with the accumulation effect in the key chains, the backbone enterprises may drive the related enterprises in the upstream and downstream to increase the possibilities of technology sharing and product matching, and further extend the linkage industry chain. With the strategic and global view, we should focus on the cultivation of a group of the world class enterprises, improve the dominating position and leading role of the enterprises in the international resource deployment and the global industry development, and strengthen the bargaining power of the enterprises in the global industry development. Lastly, the government departments should insist on the systematic thinking, relevant integrated optimization to help the clusters to improve the quality 
and efficiency step by step, rather than pursue the quantity all the time.

We should systematically coordinate the space layout and industry relevance of the advanced manufacture industry cluster, and optimize the cluster network structure. For the situation of many parks which are not strong, we should further coordinate the space layout and industry relevance. The first is to accelerate the construction of the great east river and western city science and innovation industry clusters. During the construction, we should emphasize the full chain construction, the matching of the upstream and downstream, and try to extend the industry chain to form a group of high end advanced manufacture industry clusters with good scale advantage and economic efficiency. We should optimize the infrastructure construction, and introduce the talents and have them stay here and lead a good life. The second is to continue to integrate the industrial parks. According to the industry development thinking that the projects accumulating in the park, industry cluster development, saving resources and function integrated construction, we should upgrade the layout of the park, and firmly prevent the dispersion of relevant industries in the upstream and downstream, and the unreasonable situation that the matching enterprises locate in different industrial parks.

We should fully improve the internationalization level, strengthen the international production capacity cooperation and the international competitiveness of the manufacture enterprises. Firstly, on basis of improving the international competitiveness of the manufacture enterprises, we should build certain typical and world famous trans-national corporations (we may encourage the enterprises to participate in the mergers and acquisitions and reconstruction across the areas and borders by the way of marketization investment), and encourage and promote the competent manufacture enterprises to make reasonable international operation strategy focusing on improving the international competitiveness, and integrate more international production elements and innovation resources. Secondly, we should achieve the international level in respect of the research and development technology. The manufacture industry enterprises in Hangzhou, especially the leading enterprises should have the boldness and ability to integrate the international key technology, be good at establishing the abroad research and development centers, or merge and acquire the foreign advanced research and development institutions, make use of foreign excellent talents and learn the experience of the excellent enterprises such as Ali Baba to build the global industry chain at abroad. Lastly, we should focus on the integration into the "one belt one road" construction, encourage some of the competent advanced manufacture industry clusters in Hangzhou to participate in the cooperation park construction outside the territory, try to build the "one belt one road" industry investment project database, promote the cooperation of the international production capacity and equipment manufacture to form the global trade, investment, finance, production and service network, and accelerate the cultivation of international economic cooperation and new competition advantages.

\section{CONCLUSION}

The Nineteenth Conference Report of CPC establishes that promoting our industry toward the middle-to-high end of the global value chain, and cultivating many world advanced manufacture industry clusters should be the new development notion and one of the important targets and tasks in constructing the modern economic system. This target and task is the significant decision made by the central party on basis of the present situation and main practice of the industry development (which has the important time significance), and the core connotation as well as the strategic direction of the modern economic system construction in the new era of the socialism with Chinese characteristics. Traditionally, the world advanced manufacture industry clusters accumulated in the places such as the Pearl River Delta, Shanghai, etc. However, with the good innovation and entrepreneurship atmosphere, Hangzhou has become the new place for intellectual made. Moving toward to the middle-to-high end of the global value chain is the urgent request for our industry to get rid of the difficult situation of low value chain end and value distribution. Hangzhou should adopt measures to struggle to the goal of becoming the world advanced manufacture industry clusters. During such course, on one hand, we construct Hangzhou to make it become the world advanced manufacture industry area; on the other hand, Hangzhou should be the first class in the advanced manufacture industry.

\section{AUTHORS' CONTRIBUTIONS}

Haiyan ZHOU performed the policy analyses and wrote the manuscript.

\section{ACKNOWLEDGMENTS}

This work was supported by the Major Program of the National Social Science Foundation of China [grant number 20\&ZD124], the National Social Science Foundation of China [grant numbers 21CJY024, 20BJL040, 19BJL108, 19BJL185], the National Natural Science Foundation of China [grant numbers71773115, 72174180, 72074195, 71973129, 72072162], the Philosophyand Social Science Program of Zhejiang [grant number 22NDQN290YB , 22QNYC13ZD , 21NDYD097Z], the Humanity and Social Science Foundation of Ministry of Education of China [grant numbers 21YJA790043, , 21YJA630037, 19YJA790107, 19YJA630092, 18YJA790088, 21YJCZH213]. 


\section{REFERENCES}

[1] Fratocchi L, Mauro C D, Barbieri P, Nassimbeni G, Zanoni A., "When manufacturing moves back: concepts and questions",Journal of purchasing and supply management, 2014, 20(1), pp54-59.

[2] Hu F, Xi X, Zhang Y. "Influencing mechanism of reverse knowledge spillover on investment enterprises' technological progress:An empirical examination of Chinese firms",Technological forecasting \& social change, (2021) 169: 120797.

[3] Gereffi, G., S. Frederick and P. Bamber.,"Diverse paths of upgrading in high-tech manufacturing: Costa Rica in the electronics and medical devices global value chains", Transnational Corporations, 2019,26(1),pp1-30

[4] Cheng, T., "Special Economic Zones: A Catalyst for International Trade and Investment in Unsettling Times?",Journal of World Investment \& Trade, 2019,20(1),pp32-67. 